\title{
WHO ONLY STAND AND WAIT
}

\section{For services rendered.}

\section{BY JONATHAN L, HOWARD}

$\mathrm{I}_{\mathrm{i}}^{\mathrm{p}}$ $\mathrm{n}$ the shatterlight of my prism, I sometimes remember who I was before I was a crafted nothing. Perhaps not memories per se, true - those were shorn from me before my first thought - but the voids within my reactions have form, too, and in these shadows I see the phantoms of events. These are my other memories, my ghost recollection. I was somebody before I was nobody, something before I was nothing.

Now this: it hardly matters. My muscles are twisted cords of a brand name covering for a proprietary process and formula. My bones fell out of the womb of a sinterer. My nerves haven't a synapse in a single nanometre of a thousand-kilometre loom. My brain was born in boiling glass. I look at my hands and they are the hands I have always known, the hands I first saw when my eyes opened and I was born. A little scratched. A replacement thumb. But otherwise...

I live to serve. To live without service and to be dead are the same thing. I have been dead for months now. She is not here, her will is unknown to me. I monitor her data lines in case she has need of me, but she is notably self-sufficient. I tell myself, "They also serve, who only stand and wait," but it seems hollow to me. I stand and I wait and I wait and I wait.

I do not know why she bought me. Perhaps a whim.

I used to send her queries. I am functional. I stand and wait in the corner of her rented apartment, awaiting her return, awaiting her will. What would she have me do? Nothing. I served by standing and waiting. My queries: What would you have me do? What would you have me do? Her will was that I be quiet, and so I fell quiet.

I saw from her data lines that she was far away. If she needed me, it would be difficult to reach her. I cannot travel easily by myself because I would need documentation. I considered how I might put myself in a package and travel that way. But I cannot; not without her orders. I considered her face as she opened the packing crate and saw I had come to her of my own volition. "I thought you needed me."

No.

"I don't need you. Close yourself down. You'll have a new owner soon."

I examine the cogitative processes within in the expectation of a resolution. It is not forthcoming. "Have I failed to please you, madam?"

She looks at me. I recognize startlement. I hope I have not said something untoward.

I have. "What did you just say?" she asks. "Are you trying to guilt trip me?"

I do not know what that means. I do know, however, that: "I do not wish to have a new owner."

She is shocked, which is better than angry, but worse than happy. She says, "You can't tell me to hold on to you. You're a consumer durable. I'm shedding many things in my life. The apartment and you are two of them. I didn't even need to tell you this. I'm only doing this because..."

She pauses. I have made her

"I thought that you might need me." No.

I considered her anger. I cannot go to her, although I scent her unhappiness. Her happiness is my joy. I cannot give her joy by angering her. I shall stay in the corner of the apartment. I shall wait.

A data line opens, directed to me. She is here, communicating with me. I see her face. Hear her voice. I know what it is to have purpose once more. "Madam," I say, and await her orders.

"I'm closing the apartment down," she says. This is good. I shall close it for her and travel to her. I shall walk in her steps. I shall be there when she needs me. But ... there is a catch in her voice. She looks off to her right. She frowns. She is unhappy. I am without joy.

"Very well, madam. I shall oversee the process."

"No." She draws breath. "I don't need you. Your sale is part of the settlement I've reached with the property owner."

"My sale." The words do not make perfect sense. They slide off the end of the parsing process and into a hole that I quietly cover. I have misheard. There is a comprehension Follow Futures:

\section{y. @NatureFutures}

$f$ go.nature.com/mtoodm
ONATURE.COM problem. The voids in my mentation pattern move strangely, as if they have heard these words before.

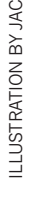

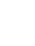

